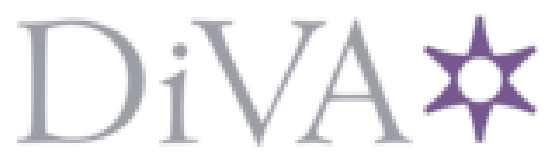

http://www.diva-portal.org

\title{
Postprint
}

This is the accepted version of a paper published in Bioresource Technology. This paper has been peerreviewed but does not include the final publisher proof-corrections or journal pagination.

Citation for the original published paper (version of record):

Svanberg, M., Olofsson, I., Floden, J., Nordin, A. (2013)

Analysing biomass torrefaction supply chain costs.

Bioresource Technology, 142: 287-296

http://dx.doi.org/10.1016/j.biortech.2013.05.048

Access to the published version may require subscription.

N.B. When citing this work, cite the original published paper.

Permanent link to this version:

http://urn.kb.se/resolve?urn=urn:nbn:se:umu:diva-79890 


\section{Analysing biomass torrefaction supply chain costs}

Martin Svanberg*, Ingemar Olofsson ${ }^{* *}$, Jonas Flodén $^{* * *}$, Anders Nordin ${ }^{* * * *}$

* Corresponding author, Ph.D. candidate, martin.svanberg@chalmers.se, Division of Logistics and Transportation, Chalmers University of Technology, SE -412 96

Göteborg, Sweden, +46 317721134

** Ingemar Olofsson, Ph.D. candidate, ingemar.olofsson@chem.umu.se, Applied Physics and Electronics, Umeå University, SE-901 87 Umeå, Sweden

*** Jonas Flodén, Ph.D., Jonas.floden@ @andels.gu.se, Logistics and Transport

Research Group, School of Business, Economics and Law, University of Gothenburg, SE 40530 Göteborg

**** Professor, Ph.D., Anders Nordin, anders.nordin@chem.umu.se, Applied Physics and Electronics, Umeå University, SE-901 87 Umeå, Sweden

Abstract: The objective of the present work was to develop a techno-economic system model to evaluate how logistics and production parameters affect the torrefaction supply chain costs under Swedish conditions. The model consists of four sub-models: (1) supply system, (2) a complete energy and mass balance of drying, torrefaction and densification, (3) investment and operating costs of a green field, stand-alone torrefaction pellet plant, and (4) distribution system to the gate of an end user. The results show that the torrefaction supply chain reaps significant economies of scale up to a plant size of about 150-200 kiloton dry substance per year (ktonDs/year), for which the total supply chain costs accounts to 31.8 euro per megawatt hour based on lower heating value (€/MWh$\left.h_{\mathrm{LHV}}\right)$. Important parameters affecting total cost are amount of available biomass, biomass premium, logistics equipment, biomass moisture content, drying 
technology, torrefaction mass yield and torrefaction plant capital expenditures (CAPEX).

Keywords: Torrefaction, pre-treatment, supply chain, logistics, system analysis

\section{Introduction}

In order to break the oil dependency and to reduce the environmental impact of the energy sector, a transition from fossil to renewable energy is needed. Among the feasible alternatives, one of the more straightforward would be to increase the use of biomass raw materials such as different kinds of forest fuels. However, forest biomass is expensive to procure due to poor transportation and handling properties, which is due to high bulk-volume and a large share of moisture content. Biomass is also costly to procure as the supply is often located far from consumption (Möller and Nielsen, 2007) and is scattered and in small quantities over large areas (Gronalt and Rauch, 2007). In order to increase the usage of forest-derived fuels, an efficient planning of the logistics activities in the form of, for example, network design is thus required. Important decisions are often about when and where the supply should be consolidated, i.e., in terminals, in order to: (1) switch transport-mode or carrier in order to increase the transport efficiency, (2) perform processing (e.g., comminution) to improve product properties and hence transportation efficiency, or (3) bridge the gap between fluctuations in both supply and demand. The location and scale of such terminals and the design of the forest fuel supply network has been studied in a number of papers (Kanzian, 2009, Gunnarsson et al., 2004, Gronalt and Rauch, 2007). Switching from truck to train is one way to increase the transport efficiency but the train transport distance has to exceed a certain length in order to overcome the transhipment cost, e.g., under North-American settings a minimum of $145 \mathrm{~km}$ (Mahmudi and Flynn, 2006) and 
135-165 km for a Finnish case (Tahvanainen and Anttila, 2011). However, even though transportation efficiency is increased through processing, consolidation of flows and switching transportation mode from truck to train or ship, unrefined biomass is still expensive to transport long distances, especially in comparison to fossil fuel such as coal. A possible future advancement to address this problem is to introduce more sophisticated pre-treatment processes in the nodes (terminals, stand-alone or possible roadside) in the supply chain. Initial processing by pyrolysis or torrefaction in order to (1) increase the efficiency of logistics activities (transport, handling and storage) and (2) enhance the value of biomass may significantly facilitate the biomass utilisation. Such decentralised pre-processing of biomass is acknowledged as an important development in order to increase the amount of biomass used for energy purposes (Richard, 2010) and especially, torrefaction is often argued as the major process in order to increase handling and transportation efficiency. In a comparison of transatlantic supply chains, it has been shown that torrefaction is the economically favourable process over pyrolysis and traditional pelletising (Uslu et al., 2008).

Torrefaction (van der Stelt et al., 2011) is the focal pre-treatment process in this paper. It is a thermal treatment process in which the biomass material is subjected to a temperature in the range of $200-350{ }^{\circ} \mathrm{C}$ in reducing or possibly slightly oxidative atmospheres (Wang et al., 2013, Li et al., 2012), during a sufficiently long residence time. Through the combined implementation of torrefaction and a subsequent densification process, torrefied densified biomass (TDB) is produced, which has superior properties compared to unrefined forest fuel and traditional pellets. Besides increasing the transportation efficiency, the enhanced characteristics add value to the product by enabling direct use of efficient and commercially available coal conversion 
technologies as well as for co-processing with coal. Ciolkosz and Wallace (2011) concluded that torrefied biomass is a suitable feedstock for coal co-combustion and gasification and Zheng et al. (2013) have shown that torrefaction is a promising method for improving bio-oil quality.

The research of pre-treatment processes in a supply chain perspective is rather sparse, e.g., Ciolkosz and Wallace (2011) found in a recent review that very few papers have examined the techno-economic aspect of a torrefaction process in the supply chain perspective. Furthermore, Svanberg and Halldórsson (2013) noted that a torrefaction plant should adapt the production strategy to the customer demand and to the supply chain. Torrefaction investment cost reaps significant advantages from economies of scale and should exceed 40 megawatt based on thermal effect ( $\left.\mathrm{MW}_{\mathrm{th}}\right)$ (Uslu et al., 2008). The operating availability has been argued as perhaps the most important parameter affecting production cost (Shah et al., 2012, Uslu et al., 2008), but moisture content is also of significant importance (Shah et al., 2012). Other important parameters affecting torrefaction cost is torrefaction severity (i.e., temperature and residence time), which when increased had a negative impact on production cost (ibid). Pirraglia et al. (2013b) found out that the production cost is sensitive to changes in CAPEX and that the selection of type of technology chosen for torrefaction and adequate binders may affect the production cost significantly. Furthermore, Pirraglia et al. (2013a) showed that biomass cost is an important variable as it represents the major component of the production cost and is sensitive to variations.

From the previous discussion, it is concluded that there is a research gap regarding (1) the design of biomass-to-energy supply chains including pre-treatment processes such 
as torrefaction and (2) regarding how to adapt torrefaction production strategy to minimize the total supply chain cost. Hence, the objective of the present work is to develop a techno-economical system model to address how logistics and torrefaction production parameters affect (1) optimal size of the torrefaction plant and (2) the total cost of supplying torrefied biomass to an end user, such as a combined heat and power plant (CHP). This paper extends earlier work by Chiueh et al. (2012) who evaluated torrefaction supply chain but assumed the same costs for centralised compared to decentralised torrefaction plants and pointed out cost as a function of level of centralisation as an important area for future research.

\section{Materials and methods}

In order to facilitate the evaluation of the economics of any torrefaction supply chain, a system model consisting of four sub-models has been developed. The present version of the model was based on Swedish conditions and consists of: (1) a supply system to a torrefaction plant, (2) a complete energy and mass balance of drying, torrefaction, heat generation and densification, (3) CAPEX and operating expenditures (OPEX), and (4) a distribution system to the gate of an end-user. The system model was applied to evaluate a feasible supply chain under Swedish conditions. The size of the torrefaction plant is proportional to the procurement area. The train distance from the torrefaction plant to the customer is set to $500 \mathrm{~km}$, based on (1) an estimation of the distance between regions of large unused potentials of biomass and location of big city areas where potential customers are located, and (2) the current length of existing bioenergy train supply chains, with an average of $468 \mathrm{~km}$ (reported by Enström and Winberg (2009) at the Swedish Institute for Forestry Research). However, the train distance is further evaluated in a sensitivity analysis. The demand is assumed to be located in the 
big city regions in Sweden and the demand pattern is based on a duration graph (energy) of a large pellet-fired CHP with a yearly production of 900 gigawatt hours (GWh) heat and 300 GWh electricity, located in Stockholm, Sweden. The CHP operates for approximately half the year. Given that the torrefaction plant operates almost the entire year, a buffer of finished TDB is assumed to be located next to the torrefaction plant. Swedish regulations for road and rail transport are assumed, which in a European comparison have a very high weight capacity.

\subsection{Supply system}

Costs for the following activities subsequent activities are included in the supply model: forwarding, covered roadside storage, comminution and road transport. In addition, there are costs for losses, administration and biomass premium paid to the forest owner. Costs for forwarding, comminution and road transport are based on an Excel model called "Flis" (originally developed by Hofsten et al. at the Swedish Institute for Forestry Research). Actors within the Swedish forestry industry have supplied additional data required for adapting the model to the focal torrefaction case as well as the costs for covered roadside storage. Cost calculations for road transport follow generic principles, consisting of cost for capital, operations and personnel; see, e.g., Chiueh et al. (2012) for detailed descriptions of modelling. Costs due to losses in handling and storage are based on values from previous research; see the compilation made by Eriksson (2008). Cost for administration and biomass premiums paid to the forest owner are based on average of values of 7 Swedish Crowns per cubic meter over bark $\left(\mathrm{SEK} / \mathrm{m}^{3} \mathrm{~s}\right)$ and 39 $\left(\mathrm{SEK} / \mathrm{m}^{3} \mathrm{~s}\right.$ ) reported by the Swedish University of Agricultural Sciences (Athanassiadis (2009) and 73,5 (SEK/ton $\mathrm{DS})$ and 172,5 (SEK/ton $\left.{ }_{\mathrm{DS}}\right)$ reported by the Swedish Institute for Forestry Research (Brunberg (2010). Feedstock yield was estimated using SLU Forest Map, Dept. of Forest Resource Management, Swedish University of Agricultural 
Sciences; see previous publications, e.g., Athanassiadis et al. (2010). Key values for the supply system are presented in Table 1 . Data are in general presented as $€ / \mathrm{MWh}_{\mathrm{LHV}}$ of delivered product as this is the unit of analysis in the supply chain.

-Insert table 1 about here-

\subsection{A production model}

The TDB production model is based on a complete energy and mass balance of a torrefaction system and has been developed to assess torrefaction costs for different system configurations. In a similar manner as an industrial white wood pellet production plant, the production of pellets from torrefied material consists of a few standard process steps supplemented with an additional torrefaction reactor, heat supply system and product cooler. The torrefaction plant can be seen in figure 1. The following discussion describes the technological and operating choices within a torrefaction plant.

-Insert figure 1 about here-

\subsubsection{Plant configurations}

Wet biomass in the form of chipped wood residues is received and tipped directly into the receiving bins. To manage fluctuations in arriving times for trucks, 4 different bins are included in the base case. The plant therefore does not have raw material storage, except for the total of 72 hours sized storage in the form of bins and silos. Rocks, stones and metal parts are then separated, whereafter the raw biomass is sieved from rejects such as oversized and overthick materials. The reject passes through a crusher and is returned to the inlet biomass flow. 
The biomass requires significant drying to reduce the bulk moisture before entering the torrefaction reactor. In the base case, this is done by an initial low temperature direct air blown belt drier (LT-drier) followed by a second high temperature indirect steam drier (HT-drier), thereafter heating and finally undergoing the actual torrefaction process where part of the biomass structure is decomposed under the release of volatiles. The inlet moisture content (MC) of the biomass to the torrefaction reactor is kept low (10\%) to keep the mixture of released volatiles combustible. Here $\mathrm{MC}$ is defined as: $\mathrm{MC}=$ $100 *$ moisture/(dry matter + moisture $)$. Except for the base case configuration, different configurations can be used for the drying system such as an LT-drier or an efficient advanced HT-drier combined with a LT-drier; see figure 1. In the combined drying system used in the base case, the heat recovery ratio of the HT-drier is set to a fixed value of $60 \%$, with the drying media re-used in the LT-drier. It is therefore possible to obtain energy consumption for drying below the theoretical evaporation of water at 0.7 kilowatt hours of heat per kilogram of evaporated water $\left(\mathrm{kWh}_{\text {heat }} / \mathrm{kg}_{\mathrm{H} 2 \mathrm{O}}\right)$.

The volatiles are combusted in a combined burning chamber for volatiles and powder from milled torrefied material, where the powder is used as start-up and auxiliary fuel, when needed. The released heat from the combustion process is transferred via flue gases to the torrefaction reactor through a heat exchanger and the remaining hot flue gases are cooled through either 1) a hot water boiler, when only a LT-drier is used, 2) a low pressure steam boiler when a HT-drier is used or 3) a high pressure steam boiler when a steam turbine for power generation is used together with a HT-drier. The air to the LT-drier can be heated by 1) hot water from flue gas condensation, 2) hot water from the hot water boiler, 3) condensation of the steam from the biomass exiting the HT-drier, or 4) a combination of the three. 
The torrefied biomass is cooled from the torrefaction temperature to below $90{ }^{\circ} \mathrm{C}$ in indirectly cooled screw coolers and the cooling energy is assumed to be released to the environment. The torrefied and cooled biomass is then milled in a hammer mill, pelletized in a standard pellet mill and further transported to storage where the different storage layouts consist of either (1) outdoor on asphalt tile without side border, 2) outdoor on asphalt tile with side border or 3 ) indoor on asphalt tile with border.

\subsubsection{Modelling approach}

The most important dimensioning parameters are plant design capacity, e.g. Name Plate Capacity (NPC) and availability factor which will determine the pellet production in $\mathrm{kton}_{\mathrm{DS}} /$ year. Other important parameters are the type of fuel and fuel moisture content, which will affect the dimensioning and selection of the biomass drying system, heat supply system and possibly also the degree of torrefaction, producing different amounts of combustible torrefaction gases. Further, when running a facility with flue gas condensation, it will be beneficial to reduce the use of auxiliary fuel in all cases since the flue gases from combustion of $100 \%$ torrefaction released gases have a high water dew point. There is also a possibility for electricity production mainly for internal consumption; however, this also requires a more expensive high-pressure steam boiler system.

Proximate and ultimate analysis for the incoming and outgoing fuels, gas composition and heating value and resulting mass flows were extracted from Prins et al. (2006) for the 2 torrefaction settings: high mass yield of $87.2 \%$ at $250{ }^{\circ} \mathrm{C}$ and 30 minutes and low mass yield of $66.8 \%$ at $300{ }^{\circ} \mathrm{C}$ and 10 minutes (see table 2). Further, a medium mass 
yield of $77.0 \%$ with the corresponding process settings of $275^{\circ} \mathrm{C}$ and 20 minutes and data for mass and energy flows could be approximated out of the former torrefaction settings. The torrefaction data for the medium mass yield are also used in the base case model calculation.

-Insert table 2 about here-

\subsection{CAPEX and OPEX}

The total production cost of densified torrefied material is based on the CAPEX and OPEX, including annual investments. CAPEX is estimated using dimensioning data from the energy- and mass balances and actual prices from existing facilities and prices from budget offers for process sizes in the region of 200-240 kton $\mathrm{DS} / \mathrm{year}$, which includes all equipment from biomass receiving to pellet storage for a complete, commercial and stand-alone torrefaction production plant. In table 3, the estimated investment costs for the base case production plant with an annual production of 200 kton Ds pellets from torrefied material are presented. For costs of plant equipment sizes below and above $200 \mathrm{kton}_{\mathrm{DS}} / \mathrm{year}$ the following approximate equation relating the cost of capital equipment as a function of size is used:

Cost $_{\text {Size } 2}=$ Cost $_{\text {Size }} 1 \times(\text { Size } 2 / \text { Size } 1)^{\text {scale factor }}$

where the scale factor is generally in the range of 0.6 to 0.8 (Jenkins, 1997, Flynn and Searcy, 2009) and in the 0.7-0.8 range for single biomass boilers and coal power plants (Bain and Overend, 2002, Flynn et al., 2003). Lower scale factors may be used for mature technology and at sites with fairly good infrastructure, and higher scale factors can be used for un-mature technology mostly at new sites with little or no infrastructure. 
For very large plants, however, the scale factor tends to reach close to unity, mostly due to the fact that parallel units will be built (Jenkins, 1997, Flynn et al., 2003). The scale factor used in the base case of the present study is set to 0.7 since the studied facilities represent the $\mathrm{n}^{\text {th }}$ torrefaction plant and should be seen as mature, using most of the equipment "off the shelf". However, recent torrefaction research (Wang et al., 2013, Li et al., 2012) have shown that it may be possible to run the torrefaction process in slightly oxidizing atmosphere rather than inert atmosphere, reducing the need for the manufacturing of expensive inert gases (i.e. nitrogen of oxygen deficient flue gases). Therefore, future development could result in both lower CAPEX in terms of less complicated torrefaction equipment and lower OPEX in terms of lower consumption of inert gases.

For capacities at and above maximum scale-up levels specified by the manufacturers, the equipment is split into 2 or more trains using the same scale factor but at smaller capacity, i.e., LT-drier with a maximum evaporation capacity of 28.8 ton water per hour

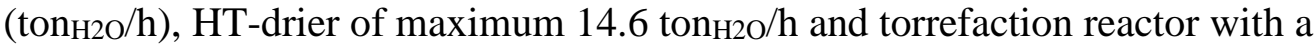
maximum inlet capacity of 32.5 ton dry substance per hour (ton $\mathrm{DS} / \mathrm{h}$ ). For the pellet machinery, a combined scale factor of 0.9 is used at all plant sizes since there will always be more than one mill due to capacity limitations.

-Insert table 3 about here-

The OPEX is calculated using a commercial spreadsheet application (DataPartner, 2012) and is based on several parameters such as the size of the plant (with energy- and mass balance), auxiliary energy consumption, price of raw materials and products, re- 
investments, maintenance, insurances, license fees, salaries, availability, contracted services, energy price, capital tied-up, inflation, interest on capital and depreciation. The fixed operational parameters for all sizes and configurations are presented in table 3 . In the spreadsheet application, the sale price of the product (income) is adjusted so that the plant net present value (NPV) is 0 when the plant has depreciated 15 years. The production cost is then calculated as the difference between the product and the starting material in $€ / \mathrm{MWh}$ of the product.

During 2012, site visits at eight Swedish pellet plants were performed to gather operational data and site experience for model development. This served as input for parts of the model construction, and in particular for estimation of personnel requirements. Personnel requirements for real existing white pellet plants and for the modelled torrefaction plant can be seen in figure 2. Personnel include operators within production, handling and maintenance, managers, and sales and marketing.

-Insert figure 2 about here-

\subsection{Distribution system}

The following subsequent activities are included in the distribution model: truck transport to sending terminal, handling at terminal, train transportation, handling at receiving terminal, and truck transport to end-user. An intermodal road-rail system has been designed for each of the production volumes. Cost calculation for the intermodal system follows calculation principles and costs detailed in Flodén (2011). The system represents a possible real-world system, including time tables, allowed train weights, number of wagons, turnaround times, terminal handling (loading, unloading, shunting), road transport to/from terminal, return of empty train and load units, assuming a general 
rail network of a high standard. At least one train departure per week has been assumed to reduce the need for intermediate storage. It is assumed that the train wagons and containers are used exclusively in the focal supply chain (expect for in the 25 $\mathrm{kton}_{\mathrm{DS}}$ /year case), but the rail engines are assumed to take other assignments when the train is not used in the current system. Compared to unrefined forest fuel for which the load is limited due to volume, TDB is limited by weight restrictions. Key data for the distribution system is presented in table 4.

-Insert table 4 about here-

\section{Results and discussion}

A comprehensive and flexible system model of a complete torrefaction supply chain was successfully developed. Results consisting of costs for the torrefaction supply chain are presented below, first on a system part level and then on an activity level. This is followed by a sensitivity analysis of a vast number of parameters for a base case of a 200 kton $\mathrm{DS} /$ year torrefaction plant, where the base-case settings can be seen in table 5 . Based on this, the optimal size of the torrefaction and total supply chain cost is then analysed for the most significant parameters. Finally, a "best-case" scenario is presented.

\subsection{Cost for different system parts of the torrefaction supply chain}

The results show that the torrefaction supply chain reaps major advantages from economies of scale for torrefaction plants up to $150-200 \mathrm{kton}$ DS $/$ year and that the cost curve of TDB at the gate of an end user then flattens out (see figure 3a). For the 200 kton $_{\mathrm{DS}} /$ year torrefaction plant, the cost for the entire supply chain sums up to 31.8 $€ / \mathrm{MWh}_{\mathrm{LHV}}$, where supply system (including biomass premium) accounts for $59.5 \%$ of the system cost, the production cost to pellets accounts for $31.0 \%$ and the distribution 
system for only $9.48 \%$. There are economies of scale for both the torrefaction plant and for the distribution system. When increasing torrefaction plant size from 25 kton $\mathrm{DS} / \mathrm{year}$ to $200 \mathrm{kton}$ Ds/year, the production cost decreases from 19.8 to $9.88 € / \mathrm{MWh}_{\mathrm{LHV}}$ (a $50 \%$ reduction) but the distribution cost only drops from $3.62 € / \mathrm{MWh}_{\mathrm{LHV}}$ to $3.02 € / \mathrm{MWh}_{\mathrm{LHV}}$ (a $16.5 \%$ reduction). There are also smaller diseconomies of scale of supplying larger plants, and when plant size increases from 25 to $200 \mathrm{kton}_{\mathrm{DS}} / \mathrm{year}$, supply cost increases from $16.7 € / \mathrm{MWh}_{\mathrm{LHV}}$ to $18.9 € / \mathrm{MWh}_{\mathrm{LHV}}$ (a $13.2 \%$ increase).

-Insert figure 3 about here-

\subsection{Costs for different activities in the torrefaction supply chain}

For a 200 kton $_{\mathrm{DS}} /$ year torrefaction plant, the activities in the system that account for the largest share of the total costs $\left(31.8 € / \mathrm{MWh}_{\mathrm{LHV}}\right)$ all belong to the biomass supply system (in total $18.9 € / \mathrm{MWh}_{\mathrm{LHV}}$ ) which are: biomass premium at $4.40 € / \mathrm{MWh}_{\mathrm{LHV}}$; comminution at $3.98 € / \mathrm{MWh}_{\mathrm{LHV}}$; road transport to torrefaction plant at $3.86 € / \mathrm{MWh}_{\mathrm{LHV}}$ and forwarding cost of $3.37 € / \mathrm{MWh}_{\mathrm{LHV}}$; see fig 4 , white bars.

Within the torrefaction plant (see grey bars in figure 4), the biomass drying system accounts for approximately $2.61 € / \mathrm{MWh}_{\mathrm{LHV}}$, followed by the steam production system at $1.89 € / \mathrm{MWh}_{\mathrm{LHV}}$, torrefaction system at $1.31 € / \mathrm{MWh}_{\mathrm{LHV}}$, and pelletizing at 1.25 $€ / \mathrm{MWh}_{\mathrm{LHV}}$. Though the drying system is configured at a highly efficient setup, it still accounts for the highest costs in the production plant due to the high heat consumption.

The costs for activities within the distribution system (see black bars in figure 4) are rather low, explained by the fact that TDB has very high energy density in combination with efficient rail transport, which makes transport and handling costs low. Still, the full 
potential advantages of TDB biomass cannot be utilised due to weight restrictions in road transports, which results in the containers only having a fill rate of $71.4 \%$ from a volume perspective.

-Insert figure 4 about here-

\subsection{Sensitivity analysis for a $200 \mathrm{kton} \mathrm{Ds} / \mathrm{year}$ plant}

The results from the sensitivity analysis of a $200 \mathrm{kton}_{\mathrm{DS}} / \mathrm{year}$ plant are shown in table 5, where variations of key parameters due to regional variances, different setups or uncertainties in data are analysed.

\subsubsection{Sensitivity analysis for the supply system}

Within the supply system, several of the parameters significantly impact the total supply chain cost such as the amount of biomass, biomass premium paid to forest owners, forwarding and transportation cost. The biomass moisture content also has a large impact on the system efficiency, as it affects both supply cost and production cost. This is due to the fact that increased moisture content decreases the amount of biomass that can be transported on each truck due to weight restrictions and the increased drying costs in the torrefaction plant.

-Insert table 5 about here-

\subsubsection{Sensitivity analysis for production}

The setup of the drying technology has a large impact on the production economy. This can be explained by the fact that the combined HT/LT-drier system is efficient, consuming as little as $0.65 \mathrm{kWh}_{\text {heat }} / \mathrm{kg}_{\mathrm{H} 2 \mathrm{O}}$ while the separate HT- and LT-driers consume about 0.90 and $1.35 \mathrm{kWh}$ heat $/ \mathrm{kg}_{\mathrm{H} 2 \mathrm{O}}$, respectively. Furthermore, both drier types consume 
quite large amounts of electricity due to the large air fans and driving motors, with the implication that the drying system should be kept as small and efficient as possible.

Given that it was assumed that the base case was a stand-alone plant without the possibility of producing residential heating, biomass moisture content below $39 \%$ will produce excess heat, which cannot be utilised in the plant. In the case of $30 \% \mathrm{MC}$, the setup was to use the excess heat in a larger LT-belt drier coupled to a smaller HT-drier, which requires quite high CAPEX of the drying system.

The torrefaction mass yield is important in several aspects since an increase in mass yield requires an increased use of torrefied powder for heat generation. A decrease has the opposite effect and will also produce excess heat in the system, which enforces a simple LT-drier system to release the excess heat to the environment due to the lack of other heat consumers. At the same time, this configuration also makes the system highly energy inefficient with increased CAPEX, which has quite a large impact on the production cost.

Changing the torrefaction plant availability to $92 \%$ or $98 \%$ will not result in any major impact on total costs. An implementation of power generation would actually increase the OPEX, which is mostly explained by an increase in plant CAPEX of about $20 \%$, to a great extent due to the steam boiler (producing 20.5 ton per hour of steam at 60 bar $_{\text {a }}$ and $470{ }^{\circ} \mathrm{C}$ ). Furthermore, the specified adiabatic coefficient of performance of the small back pressure steam turbine is also quite low (68\%), which limits the possible power outtake. The plant electricity consumption is 3.63 megawatt electrical $\left(\mathrm{MW}_{\mathrm{e}}\right)$ while the production is $2.25 \mathrm{MW}_{\mathrm{e}}$, resulting in a required net purchase of $1.37 \mathrm{MW}_{\mathrm{e}}$. 
The plant would need to purchase electricity for all studied sizes but the relative consumption should decrease for larger sized plants due to more efficient driving systems and a somewhat increased adiabatic coefficient of performance of the steam turbine.

For combustion of pure torrefaction gases, flue gas condensation will be beneficial due to the high moisture content in the flue gases, whereas a system based on dry powder fuel will not benefit as much. The base case system setup is close to energy selfsustaining by the torrefaction gas and thus the use of auxiliary fuel is low. In this setup, the benefits are instead limited by excess heat problems. Therefore, adding a quite small flue gas condensation unit (much smaller than the available amount of heat) will only decrease total system cost by $1.2 \%$. However, if biomass with higher moisture content is used in the base case setup (requiring more drying heat) and/or adjusting the torrefaction mass yield to a minimum use of auxiliary fuel, at the same time as flue gas condensation is used to its maximum, the cost reduction of $1.2 \%$ would at least be doubled compared to the base case, resulting in a highly energy efficient system.

\subsubsection{Sensitivity analysis for the distribution system}

The results from the sensitivity analysis of the distribution system show that no parameter has any major impact, where the effect of the largest is limited to about $1.7 \%$ of total cost. First of all, the train distance has no major impact. This can be explained by the very large energy volumes on the trains due to the high density of the TDB and the fact that once the train is running, increasing the distance does not affect total system cost much, e.g., an increase of $250 \mathrm{~km}(+50 \%)$, results in an extra cost of 0.55 $€ / \mathrm{MWh}_{\mathrm{LHV}}$ which is an increase of $1.7 \%$ of the total system cost. Secondly, increasing the road distance to terminals only has minor effects as well, e.g., a $50 \%$ increase only 
renders a $0.1 \%$ increase. Even a tenfold increase, which could for example occur if there is a suitable spot for torrefaction integration with other industries far from rail terminals, only results in a $2.0 \%$ increase. Thirdly, if the torrefaction plant is located close to the rail track and the customer is located close to the receiving terminal, eliminating the need for road transports within the distribution system, the fill rate in the load units would be increased from $71.4 \%$ to $84.9 \%$ from a volume perspective. However, this setup only results in a reduction of $0.69 € / \mathrm{MWh}_{\mathrm{LHV}}$ (a decrease of $2.2 \%$ of the total system cost).

\subsection{Sensitivity analysis for different plant sizes}

Below, nine parameters are further analysed as functions of plant size. These are comprised by the eight most important parameters from table 5 complemented by the scale factor, which did not show any impact as most prices were obtained for the plant producing 200 kton $D S / y e a r$. The scale factor therefore needs closer analysis for different torrefaction plant sizes.

Biomass premium and forwarding cost had very similar impacts on cost (see figure $3 \mathrm{c}$ ). These had no major effect on optimal size, but rather shifted the entire curve up and down. The type of equipment had a large impact on both the cost and optimal size. The cost is generally higher for the truck with an integrated chipper. The differences are rather small for small sizes but much larger for large sizes, and the difference compared to a regular truck increases with increasing plant size due to longer driving distances for which the truck with an integrated chipper is inefficient. Whereas the curve is flat for the regular truck, the truck with an integrated chipper starts rising at 150 kton Ds/year. Hence, the logistics equipment need to be selected based on the desired size of the torrefaction plant. 
An increase in the biomass moisture content to $50 \%$ has a large impact on the total system cost, whereas a lower moisture content (30\%) does not affect the system cost as much; see figure $3 \mathrm{~d}$. The actual change in kilograms of water per kilogram of dry substance is the same for the high and low level compared to the base case and the negative effect from the high level of biomass $\mathrm{MC}$ is due to the increased use of auxiliary fuel, whereas a lower inlet MC produces excess heat when the mass yield and optimal drying configuration is maintained. Therefore, the size of the LT-drier has to be increased from the optimal size, making the drying configuration less efficient. This problem can be counteracted by increasing the torrefaction mass yield, which maintains an efficient drying configuration. The optimal plant size further is almost unaffected by a change in $\mathrm{MC}$.

The amount of biomass available within a region can vary as a function of yield per area and due to competition. This has a major impact on both cost and optimal size of the torrefaction plant. For low amounts of available biomass (-50\%), the optimal size occurs at 150 kton $D S / y e a r$, but after that, the curve rises. For high amount of biomass $(+50 \%)$ the curve is rather flat after a plant size of $250 \mathrm{kton}$ DS/year. The implication for selecting the size of the torrefaction plant is that, for areas with lots of biomass, there is a higher degree of freedom on which size should be built, whereas in areas with little biomass, there is one "best" or a smaller size span to select within.

Changes in CAPEX naturally have significant effects on total system costs (figure 3e). Smaller plants are also more affected by changes in CAPEX than larger plants, which is due to economies of scale. The impact from changes in CAPEX on total system cost for 
very small plants is almost doubled compared to plants at sizes over $250 \mathrm{kton}_{\mathrm{DS}} / \mathrm{year}$. For high CAPEX, the optimal size is shifted to sizes above $300 \mathrm{kton}$ DS/year.

In figure $3 f$, it can clearly be seen that the uncertainty of what scale factor that is used (0.6-0.8) is not critical to the results for the present conditions and only small effects were obtained on the total system costs. While a scale factor of 0.8 decreases the CAPEX for smaller plants it increases the CAPEX for larger plants. A scale factor of 0.6 does the opposite. Further, small plants are more affected by the scale factor due to economy of scale and the optimal size is only marginally affected.

Compared to the base case setup and conditions, changing mass yields and drying system configurations all result in increased total system costs, which can be seen in figure 3f. Decreasing the mass yield from $77.0 \%$ to $66.8 \%$ results in significantly higher total system costs, whereas an increase of the mass yield only marginally increases the costs. For a low mass yield, the gas production and thus excess heat production is far too high to be combined with an efficient combined drying system, wherefore an inefficient LT-drying setup has to be used with increased biomass consumption/cost and hugely increased OPEX as a result.

The total costs for the LT-drying with base case mass yield (figure 3f, topmost line) are almost the same as the setup for the lower mass yield with LT-drier. There is, however, an advantage for the lower mass yield setup due to an actual increase in production capacity in terms of megawatt hours based on lower heating value (MWhLHV) and a positive effect on the product distribution cost by a decrease of $3.5 \%$ due to increased energy density of the product. The increased biomass consumption puts the total system 
cost on the same level for larger plant sizes and for both mass yields with LT-drier setups, and also pushes the optimal plant size to lower production volumes. The HTdrier setup will, like the LT-drier setups, consume more energy per evaporated unit of water with both the costs for increased biomass consumption and increased OPEX. Compared to the LT-drier setup, however, the impact is not as large.

Finally, an increase in mass yield to $87.2 \%$ will decrease the torrefaction gas yield, which in turn will increase the need for auxiliary fuel but also reduce the energy density of TDB. Since the production capacity is based on kton ${ }_{D S}$ rather than $\mathrm{MWh}_{\mathrm{LHV}}$, the plant production in terms of MWh $\mathrm{LHV}_{\mathrm{L}}$ actually decreases compared to the base case. This has a negative effect, but mostly for the smaller plants (figure $3 \mathrm{f}$, dotted line), due to relatively increased CAPEX and OPEX, but a limited positive effect on supply cost due to decreased biomass demand. Further, the transport cost of the TDB is negatively affected (increase of $4.4 \%$ ) by increasing the mass yield compared to the base case.

To summarise, it is recommended to run the torrefaction plant using the most efficient drying technology, which implies that if the moisture content is low (for the base case below $39 \%$ ), either there has to be a heat sink of some kind, e.g., a district heating net to run the process at medium or low mass yield, or the mass yield has to be increased to reduce the torrefaction gas flow, i.e., to make use of the excess heat produced.

\subsection{Analysis of "best-case" scenario}

Finally, the results from an evaluation of lowest possible torrefaction supply chain costs are presented. This can be seen as a "best-case" scenario based on simultaneously adjusting several parameters to their feasible "best" values. A short justification for the qualified assumptions of parameters and the values can be seen in table 6 . 
-Insert table 6 about here-

It figure $3 \mathrm{~b}$ it can be seen that in the "best-case" scenario, the total supply costs are drastically decreased, in this case by about $11.6 \%$, from 31.8 to $28.2 € / \mathrm{MWh}_{\mathrm{LHV}}$ for plant sizes larger than 250 kton $_{D S} / y e a r$. Further, the optimal plant size is shifted to above 250 kton $\mathrm{DS} / \mathrm{year}$. The corresponding plant CAPEX for the two system configurations are also shown in figure $3 \mathrm{~b}$, with the "best-case" scenario representing costs that could be seen as a basis for future green-field and stand-alone torrefaction plant establishments.

\section{Conclusions}

The torrefaction supply chain reaps economies of scale up to a plant size of 150-200 kton $_{\text {DS }} /$ year. For a 200 kton $_{D S} /$ year plant, the total supply cost accounts to 31.8 $€ / \mathrm{MWh}_{\mathrm{LHV}}$, in which the supply system accounts for $59.5 \%$ of the total cost, whereas the production cost accounts for $31.0 \%$ and the distribution system for only $9.48 \%$. Parameters affecting total cost are amount of available biomass, biomass premium, logistics equipment, biomass moisture content, drying technology, torrefaction mass yield and torrefaction plant CAPEX. Parameters affecting optimal size of the torrefaction plant were drying system, CAPEX, amount of available biomass and logistics equipment.

\section{Acknowledgements}

Financial support from the Swedish Energy Agency, EC FP7 through the SECTOR project and TRB Sverige AB are gratefully acknowledged. We also thank Bio4Energy a strategic research environment appointed by the Swedish government - for supporting 
the work. We would also like to thank Henrik Von Hofsten, Skogforsk and Dimitris

Athanassiadis, Swedish University of Agricultural Sciences.

\section{References}

1. Athanassiadis, D., Lundström, A., Wikström, P., Matisons, M. \& Nordfjell, T. 2010. Is there enough primary forest fuel available to feed into the existing and planned CHP facilities? The case of Northern Sweden. Forest Bioenergy 2010. Jyväskylä: FINBIO - The Bioenergy Association of Finland.

2. Bain, R. L. \& Overend, R. P., 2002. Biomass for heat and power. Forest Products Journal. 52, 12-19.

3. Chiueh, P.-T., Lee, K.-C., Syu, F.-S. \& Lo, S.-L., 2012. Implications of biomass pretreatment to cost and carbon emissions: Case study of rice straw and Pennisetum in Taiwan. Bioresource Technology. 108, 285-294.

4. Ciolkosz, D. \& Wallace, R., 2011. A review of torrefaction for bioenergy feedstock production. Biofuels, Bioproducts and Biorefining. 5, 317-329.

5. DataPartner 2012. Invest for Excel. Stockholm.

6. Eriksson, L. N., 2008. Comparative analyses of forest fuels in a life cycle perspective with a focus on transport systems. Resources, Conservation and Recycling. 52, 1190-1197.

7. Flodén, J. 2011. Rail freight costs - Some basic cost estimates for intermodal transport. University of Gothenburg.

8. Flynn, P. \& Searcy, E., 2009. The Impact of Biomass Availability and Processing Cost on Optimum Size and Processing Technology Selection. Applied Biochemistry and Biotechnology. 154, 271-286.

9. Flynn, P. C., Kumar, A. \& Cameron, J. B., 2003. Biomass power cost and optimum plant size in western Canada. Biomass \& Bioenergy. 24, 445-464.

10. Gronalt, M. \& Rauch, P., 2007. Designing a regional forest fuel supply network. Biomass and Bioenergy. 31, 393-402.

11. Gunnarsson, H., Rönnqvist, M. \& Lundgren, J. T., 2004. Supply chain modelling of forest fuel. European Journal of Operational Research. 158, 103-123.

12. Jenkins, B. M., 1997. A comment on the optimal sizing of a biomass utilization facility under constant and variable cost scaling. Biomass \& Bioenergy. 13, 1-9.

13. Kanzian, C., Holzleitner, F., Stampfer, K. \&Aschton, S., 2009. Regional energy wood logistics - optimizing local fuel supply. Silva Fennica. 43, 113-128.

14. Li, H., Liu, X., Legros, R., Bi, X. T., Lim, C. J. \& Sokhansanj, S., 2012. Torrefaction of sawdust in a fluidized bed reactor. Bioresource Technology. 103, 453-458.

15. Mahmudi, H. \& Flynn, P., 2006. Rail vs truck transport of biomass. Applied Biochemistry and Biotechnology. 129, 88-103.

16. Möller, B. \& Nielsen, P. S., 2007. Analysing transport costs of Danish forest wood chip resources by means of continuous cost surfaces. Biomass and Bioenergy. 31, 291-298.

17. Pirraglia, A., Gonzalez, R., Denig, J. \& Saloni, D., 2013a. Technical and Economic Modeling for the Production of Torrefied Lignocellulosic Biomass for the U.S. Densified Fuel Industry. Bioenergy Research. 6, 263-275.

18. Pirraglia, A., Gonzalez, R., Saloni, D. \& Denig, J., 2013b. Technical and economic assessment for the production of torrefied ligno-cellulosic biomass pellets in the US. Energy Conversion and Management. 66, 153-164.

19. Prins, M. J., Ptasinski, K. J. \& Janssen, F. J. J. G., 2006. More efficient biomass gasification via torrefaction. Energy. 31, 3458-3470.

20. Richard, T. L., 2010. Challenges in Scaling Up Biofuels Infrastructure. Science. 329, 793-796. 
21. Shah, A., Darr, M. J., Medic, D., Anex, R. P., Khanal, S. \& Maski, D., 2012. Techno-economic analysis of a production-scale torrefaction system for cellulosic biomass upgrading. Biofuels, Bioproducts and Biorefining. 6, 45-57.

22. Svanberg, M. \& Halldórsson, Á., 2013. Supply chain configuration for biomass-to-energy: The case of torrefaction. International Journal of Energy Sector Management. 7, 65-83.

23. Tahvanainen, T. \& Anttila, P., 2011. Supply chain cost analysis of long-distance transportation of energy wood in Finland. Biomass and Bioenergy. 35, 3360-3375.

24. Uslu, A., Faaij, A. P. C. \& Bergman, P. C. A., 2008. Pre-treatment technologies, and their effect on international bioenergy supply chain logistics. Techno-economic evaluation of torrefaction, fast pyrolysis and pelletisation. Energy. 33, 1206-1223.

25. van der Stelt, M. J. C., Gerhauser, H., Kiel, J. H. A. \& Ptasinski, K. J., 2011. Biomass upgrading by torrefaction for the production of biofuels: A review. Biomass and Bioenergy. 35, 3748-3762.

26. Wang, C., Peng, J., Li, H., Bi, X. T., Legros, R., Lim, C. J. \& Sokhansanj, S., 2013. Oxidative torrefaction of biomass residues and densification of torrefied sawdust to pellets. Bioresource Technology. 127, 318-325.

27. Zheng, A., Zhao, Z., Chang, S., Huang, Z., Wang, X., He, F. \& Li, H., 2013. Effect of torrefaction on structure and fast pyrolysis behavior of corncobs. Bioresource Technology. 128, 370-377. 
Table 1 . Supply system costs

\begin{tabular}{lll}
\hline Cost factor & Value & Unit \\
\hline Forwarding & 3.37 & $€ / \mathrm{MWh}_{\mathrm{LHV}}$ \\
Loss in forwarding & 2 & $\%$ \\
Loss in roadside storing & 15 & $\%$ \\
Loss in comminution & 10 & $\%$ \\
Administration & 1.66 & $€ / \mathrm{MWh}$ \\
Premium paid to forest owner & 4.40 & $\mathrm{MWh}_{\mathrm{LHV}} / \mathrm{km}_{2} / \mathrm{yr}$ \\
Biomass yield & 7.50 & unitless \\
Winding coefficient & 1.35 & $€ / \mathrm{MWh}$ \\
Covered storage cost & 0.33 & $\%$ \\
Biomass moisture content & 42 & $€ / \mathrm{MWh}_{\mathrm{LHV}}$ \\
Comminution cost & 3.98 & $€ / \mathrm{MWh}_{\mathrm{LHV}}$ \\
Road transportation cost for a 200 ton $_{\mathrm{DS}} /$ year plant & 3.86 & \\
\hline
\end{tabular}




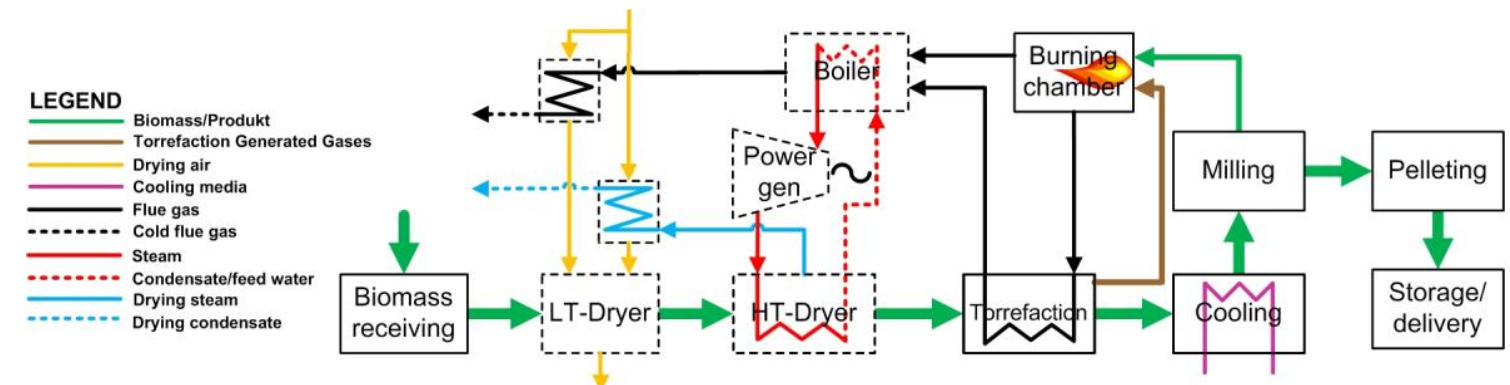

Figure 1 - Illustration of the basic flows and units included in the TDB production model (optional/changeable processes with broken lines) 
Table 2. Composition of solid and gaseous compounds from torrefaction of willow

\begin{tabular}{|c|c|c|c|c|}
\hline Torrefaction settings & Ref & High my & Medium my & Low my \\
\hline Mass yield $\left(\mathrm{m}_{\mathrm{y}}\right)(\%)$ & -- & 87.2 & 77.0 & 66.8 \\
\hline Temperature $\left({ }^{\circ} \mathrm{C}\right)$ & -- & 250 & 275 & 300 \\
\hline Time (minutes) & -- & 30.0 & 20.0 & 10.0 \\
\hline \multicolumn{5}{|l|}{ Solid products } \\
\hline Carbon, C (\%-mass $\mathrm{DS})$ & 47.2 & 51.3 & 53.6 & 55.8 \\
\hline Hydrogen, $\mathrm{H}(\%$-mass $\mathrm{DS})$ & 6.1 & 5.90 & 5.75 & 5.60 \\
\hline Oxygen, $\mathrm{O}(\%$-mass $\mathrm{DS})$ & 45.1 & 40.9 & 38.6 & 36.2 \\
\hline Nitrogen, N (\%-mass $\left.{ }_{\mathrm{DS}}\right)$ & 0.3 & 0.40 & 0.45 & 0.50 \\
\hline $\operatorname{Ash}(\%$-mass $\mathrm{DS})$ & 1.3 & 1.50 & 1.70 & 1.90 \\
\hline LHV (MJ/kg & 17.6 & 19.4 & 20.3 & 21.0 \\
\hline \multicolumn{5}{|l|}{ Gaseous products } \\
\hline Steam - dehydration $\left(\mathrm{kg} / \mathrm{kg}_{\mathrm{DS}, \text { in }}\right)$ & -- & 0.057 & 0.0615 & 0.066 \\
\hline Acetic Acid, $\mathrm{CH}_{3} \mathrm{COOH}$ (incl. other org.) ( $\left.\mathrm{kg} / \mathrm{kg}_{\mathrm{DS} \text {,in }}\right)$ & -- & 0.039 & 0.1265 & 0.214 \\
\hline $\mathrm{CO}_{2}\left(\mathrm{~kg} / \mathrm{kg}_{\mathrm{DS} \text {, in }}\right)$ & -- & 0.029 & 0.0345 & 0.040 \\
\hline $\mathrm{CO}\left(\mathrm{kg} / \mathrm{kg}_{\mathrm{DS}, \mathrm{in}}\right)$ & -- & 0.003 & 0.0075 & 0.012 \\
\hline
\end{tabular}


Table 3. CAPEX and fixed OPEX parameters for the base case configuration

\begin{tabular}{|c|c|c|c|}
\hline CAPEX, by device & M€ & CAPEX, by task & M€ \\
\hline Infrastructure and buildings & 5.95 & Infrastructure & 3.36 \\
\hline Tipping bunkers, fuel processing & 6.55 & Buildings & 3.71 \\
\hline Low temperature direct air blown belt drier & 2.27 & Machines & 23.0 \\
\hline High temperature indirect steam drier & 4.41 & $\begin{array}{l}\text { Piping, automation, } \\
\text { electricity }\end{array}$ & 4.44 \\
\hline Torrefaction reactor & 5.51 & Construction & 5.65 \\
\hline Steam boiler (fuelled by powder and TF-gas) & 11.1 & Fire protection & 0.81 \\
\hline Product cooling & 1.12 & Mounting, insulation & 2.66 \\
\hline Milling & 0.27 & Projecting & 1.92 \\
\hline Pelletizing and cooling & 5.07 & Total CAPEX & 45.5 \\
\hline Discharging and outdoor storage & 3.22 & & \\
\hline Total CAPEX & 45.5 & & \\
\hline Average capital tied-up in product storage & 7.65 & & 7.65 \\
\hline Fixed operational parameters & Value & Unit & \\
\hline Scheduled maintenance per year & 14.0 & days & \\
\hline District heating for sale & 0 & $\mathrm{MW}_{\text {Heat }}$ & \\
\hline Re-investments (under 3 years) & 1.00 & $\% / y e a r$ of CAPEX & \\
\hline Maintenance $(0.5,0.8,1,1.5$ during the first 4 years $)$ & 2.00 & $\% /$ year of CAPEX & \\
\hline Insurance & 0.50 & $\begin{array}{l}\% / \text { year of CAPEX }+c \\
\text { up in storage }\end{array}$ & tied- \\
\hline Inflation & 2.00 & $\%$ & \\
\hline Short term loans & 1.50 & $\% / y e a r$ of CAPEX & \\
\hline Scale factor of electricity consumption & 0.70 & unitless & \\
\hline Scale factor of pellet mills & 0.90 & unitless & \\
\hline Availability during the first and second production year & $65 \& 85$ & $\%$ & \\
\hline Depreciation & 15.0 & years & \\
\hline Net present value after depreciation & 0 & $\mathrm{M} €$ & \\
\hline Total cost salaried employee (during working hours) & 47.4 & $€ / h$ & \\
\hline Total cost shift worker (during working hours) & 35.2 & $€ / h$ & \\
\hline Total cost daytime worker (during working hours) & 31.3 & $€ / \mathrm{h}$ & \\
\hline
\end{tabular}




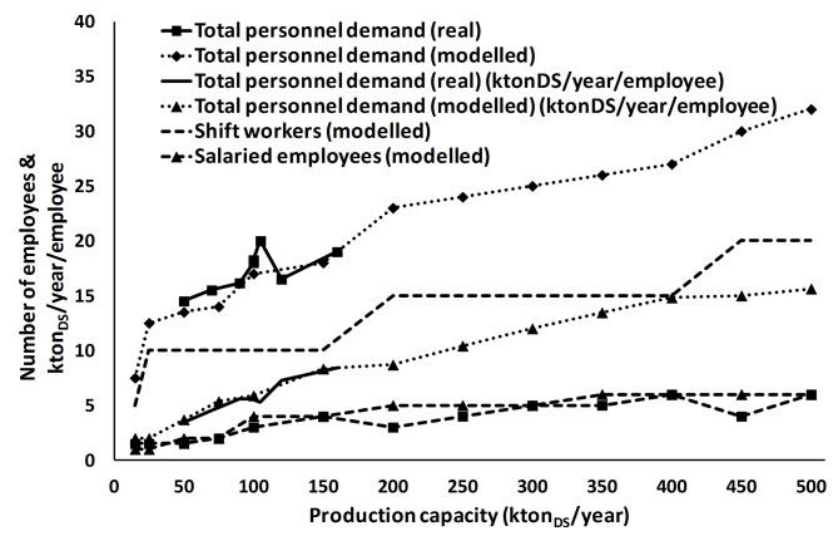

Figure 2 - Personnel demands for real white pellet plants and for the modelled torrefaction pellet plant 
Table 4. Key data for the distribution system

\begin{tabular}{lll}
\hline Activities and parameters & Value & Unit \\
\hline Wagon type & sgnss & unitless \\
Type of load unit & Generic $20^{\prime}$ bulk container & unitless \\
Number of load units per wagon & 3 & unitless \\
Number of load units per truck & 2 & unitless \\
Road distance to sending terminal & 5 & $\mathrm{Km}$ \\
Train distance & 500 & $\mathrm{Km}$ \\
Road distance from receiving terminal to CHP & 5 & $\mathrm{Km}$ \\
Number of load units per road truck & 2 & unitless \\
Energy content per container & 99.1 & $\mathrm{MWh}$ \\
Cost for 5 km road transport and handling & 1.56 & $€ / \mathrm{MWh}_{\mathrm{LHV}}$ \\
Cost for terminal handling, including shunting & 1.23 & $€ / \mathrm{MWh}_{\mathrm{LHV}}$ \\
Cost for 500 km train transport & 1.38 & $€ / \mathrm{MWh}_{\mathrm{LHV}}$ \\
\hline
\end{tabular}



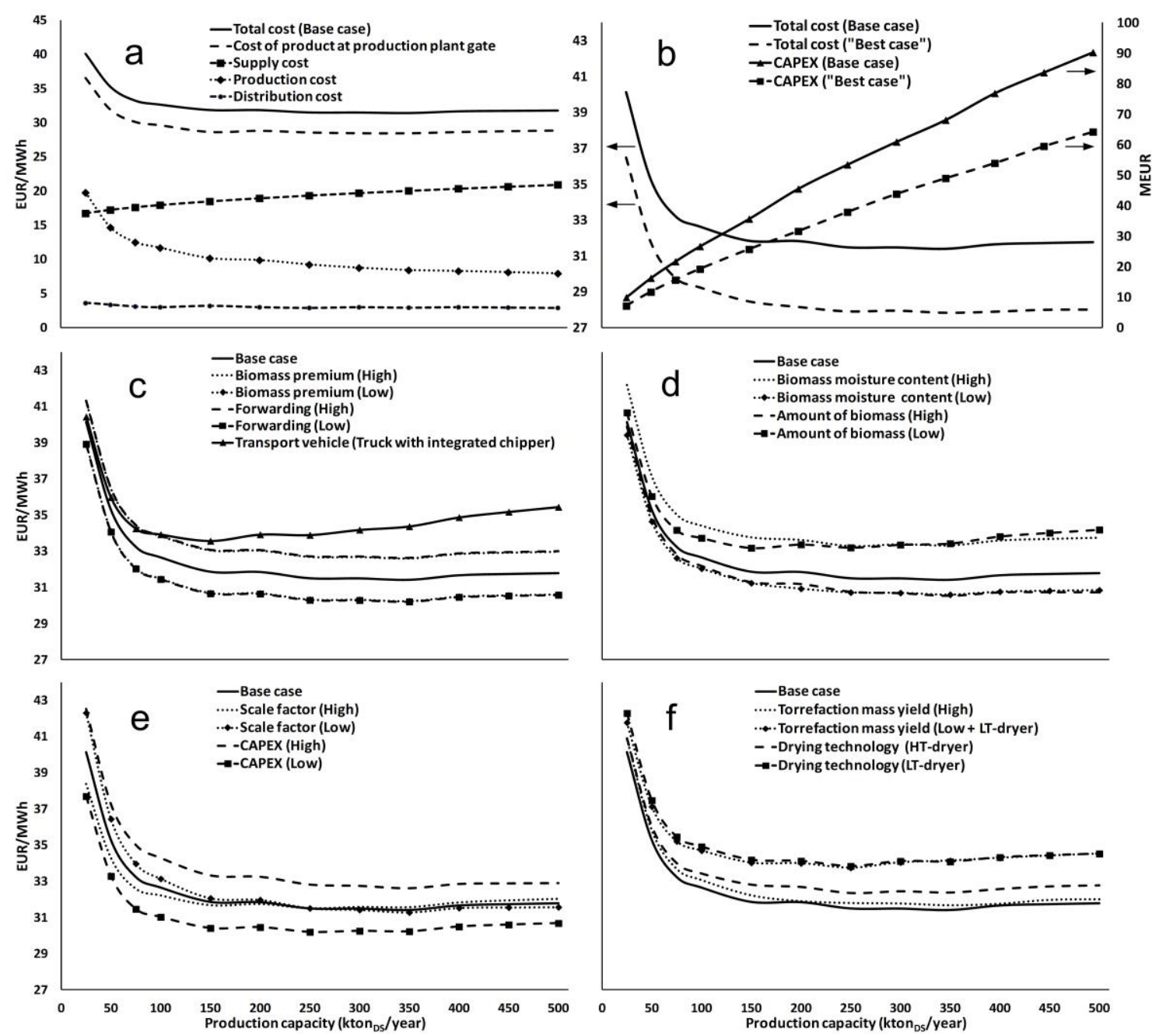

Figure 3. Torrefaction supply chain costs for: (a) different system parts in the base case scenario, (b) comparison between the base case and a "best case" scenario, and (c-f) variations of different parameters compared to the base case (represented by black continuous lines). 


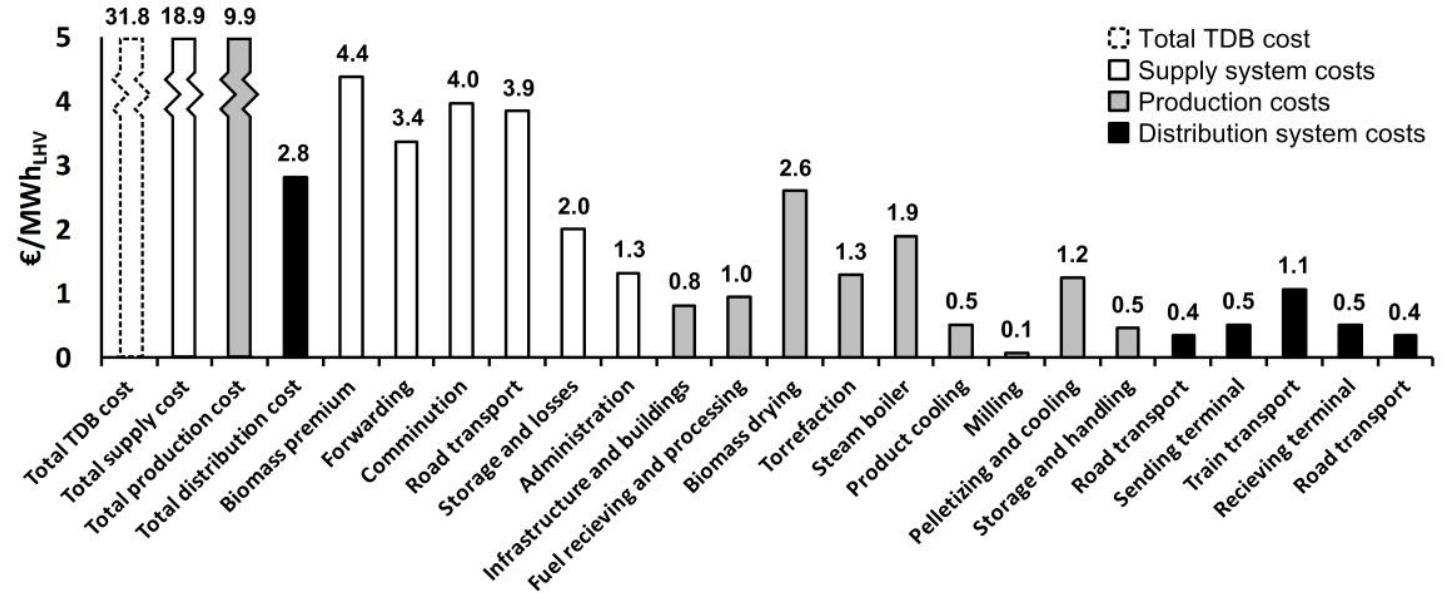

Figure 4. Costs for different system activities 
Table 5. Sensitivity analysis of the most important parameters affecting the supply, production, distribution and total supply costs

\begin{tabular}{|c|c|c|c|c|c|c|c|}
\hline & Base case & Unit & $\begin{array}{l}\text { Parameter } \\
\text { level/ change }\end{array}$ & $\begin{array}{l}\text { Supply } \\
\text { cost }\end{array}$ & $\begin{array}{l}\text { Prod. } \\
\text { cost }\end{array}$ & $\begin{array}{l}\text { Distr. } \\
\text { cost }\end{array}$ & $\begin{array}{l}\text { Total } \\
\text { cost }\end{array}$ \\
\hline \multicolumn{8}{|c|}{ Supply system parameters } \\
\hline \multicolumn{2}{|c|}{$\begin{array}{l}\text { Biomass moisture } \\
\text { content }\end{array}$} & $\%$ & $30 \%$ & $-4.6 \%$ & $-0.5 \%$ & $0.0 \%$ & $-2.9 \%$ \\
\hline \multirow{2}{*}{$\begin{array}{l}\text { Amount of } \\
\text { biomass }\end{array}$} & \multirow{2}{*}{7.50} & ton $_{\mathrm{DS}} / \mathrm{km}_{2} /$ & $50 \%$ & $4.8 \%$ & $8.6 \%$ & $0.0 \%$ & $5.6 \%$ \\
\hline & & $\mathrm{yr}$ & $-50 \%$ & $7.5 \%$ & $1.0 \%$ & $0.0 \%$ & $4.8 \%$ \\
\hline \multirow{2}{*}{ Biomass premium } & \multirow{2}{*}{4.40} & \multirow{2}{*}{$€ / \mathrm{MWh}_{\mathrm{LHV}}$} & $+25 \%$ & $5.8 \%$ & $0.8 \%$ & $0.0 \%$ & $3.7 \%$ \\
\hline & & & $-25 \%$ & $-5.8 \%$ & $-0.8 \%$ & $0.0 \%$ & $-3.7 \%$ \\
\hline $\begin{array}{l}\text { Logistics } \\
\text { equipment }\end{array}$ & $\begin{array}{l}\text { Separate } \\
\text { comminution } \\
\& \text { transportation }\end{array}$ & unitless & $\begin{array}{l}\text { Joint } \\
\text { comminut. \& } \\
\text { transportation }\end{array}$ & $10.2 \%$ & $1.4 \%$ & $0.0 \%$ & $6.5 \%$ \\
\hline \multirow{2}{*}{ Winding factor } & \multirow{2}{*}{1.34} & \multirow{2}{*}{ unitless } & 1.42 & $1.1 \%$ & $0.1 \%$ & $0.0 \%$ & $0.7 \%$ \\
\hline & & & 1.26 & $-1.1 \%$ & $-0.1 \%$ & $0.0 \%$ & $-0.7 \%$ \\
\hline \multirow{2}{*}{$\begin{array}{l}\text { Cost of road } \\
\text { transports }\end{array}$} & \multirow{2}{*}{3.86} & \multirow{2}{*}{$€ / \mathrm{MWh}_{\mathrm{LHV}}$} & $+25 \%$ & $5.1 \%$ & $0.7 \%$ & $0.0 \%$ & $3.2 \%$ \\
\hline & & & $-25 \%$ & $-5.1 \%$ & $-0.7 \%$ & $0.0 \%$ & $-3.2 \%$ \\
\hline \multirow{2}{*}{$\begin{array}{l}\text { Cost of } \\
\text { forwarding }\end{array}$} & \multirow{2}{*}{3.37} & \multirow{2}{*}{$€ / \mathrm{MWh}_{\mathrm{LHV}}$} & $+25 \%$ & $5.9 \%$ & $0.8 \%$ & $0.0 \%$ & $3.8 \%$ \\
\hline & & & $-25 \%$ & $-5.9 \%$ & $-0.8 \%$ & $0.0 \%$ & $-3.8 \%$ \\
\hline \multicolumn{8}{|c|}{ Production configuration parameters } \\
\hline \multirow{2}{*}{$\begin{array}{l}\text { Availability } \\
\text { during operation }\end{array}$} & \multirow{2}{*}{95} & \multirow{2}{*}{$\%$} & $98 \%$ & $0.0 \%$ & $-2.3 \%$ & $0.0 \%$ & $-0.7 \%$ \\
\hline & & & $92 \%$ & $0.0 \%$ & $0.8 \%$ & $0.0 \%$ & $0.2 \%$ \\
\hline Tupe of drier & Comb. HT- drier & unitlocs & HT-drier & $0.3 \%$ & $7.9 \%$ & $0.0 \%$ & $2.6 \%$ \\
\hline гуре ол unter & and LT-drier & umtiess & LT-drier & $0.9 \%$ & $21.3 \%$ & $0.0 \%$ & $7.1 \%$ \\
\hline Torrefaction mass & 770 & $\%$ & $87.2 \%$ & $-0.4 \%$ & $0.0 \%$ & $3.9 \%$ & $0.2 \%$ \\
\hline yield & 11.0 & 70 & $66.8 \%$ & $1.3 \%$ & $20.3 \%$ & $-3.1 \%$ & $6.8 \%$ \\
\hline Power generation & $\begin{array}{l}\text { No power } \\
\text { generation }\end{array}$ & unitless & $\begin{array}{l}\text { Power } \\
\text { generation }\end{array}$ & $0.2 \%$ & $4.4 \%$ & $0.0 \%$ & $1.5 \%$ \\
\hline $\begin{array}{l}\text { Flue gas } \\
\text { condensation }\end{array}$ & $\begin{array}{l}\text { No flue gas } \\
\text { condensation }\end{array}$ & unitless & $\begin{array}{l}\text { Flue gas } \\
\text { condensation }\end{array}$ & $-0.1 \%$ & $-3.5 \%$ & $0.0 \%$ & $-1.1 \%$ \\
\hline Type of product & Outdoor storage & Unit & $\begin{array}{l}\text { Indoor with } \\
\text { border }\end{array}$ & $0.0 \%$ & $2.4 \%$ & $0.0 \%$ & $0.8 \%$ \\
\hline storage & with side border & unitiess & $\begin{array}{l}\text { Outdoor no } \\
\text { border }\end{array}$ & $0.0 \%$ & $0.3 \%$ & $0.0 \%$ & $0.1 \%$ \\
\hline CAPEX/OPEX par & ameters & & & & & & \\
\hline Scale factor & 070 & unitless & 0.80 & $0.0 \%$ & $-1.1 \%$ & $0.0 \%$ & $-0.3 \%$ \\
\hline & & & 0.60 & $0.0 \%$ & $1.3 \%$ & $0.0 \%$ & $0.4 \%$ \\
\hline Change in price of & 56.6 & $€ / \mathrm{MWh}_{\mathrm{e}}$ & $+25 \%$ & $0.0 \%$ & $3.4 \%$ & $0.0 \%$ & $1.0 \%$ \\
\hline electricity & 50.0 & E/IVIW $\mathrm{H}_{\mathrm{e}}$ & $-25 \%$ & $0.0 \%$ & $-3.4 \%$ & $0.0 \%$ & $-1.0 \%$ \\
\hline $\begin{array}{l}\text { Cost of external } \\
\text { services }(1.0 \% \text { of }\end{array}$ & 0.455 & M€/year & $+50 \%$ & $0.0 \%$ & $2.2 \%$ & $0.0 \%$ & $0.7 \%$ \\
\hline investment/year) & & & $-50 \%$ & $0.0 \%$ & $-2.2 \%$ & $0.0 \%$ & $-0.7 \%$ \\
\hline Cost of nersonnel & 17 & M€/vear & $+25 \%$ & $0.0 \%$ & $4.2 \%$ & $0.0 \%$ & $1.3 \%$ \\
\hline & & lvie/yeal & $-25 \%$ & $0.0 \%$ & $-4.2 \%$ & $0.0 \%$ & $-1.3 \%$ \\
\hline CAPEX & 45.5 & $\mathrm{M} €$ & $+25 \%$ & $0.0 \%$ & $14.1 \%$ & $0.0 \%$ & $4.4 \%$ \\
\hline САГЕ & 45.3 & IVIE & $-25 \%$ & $0.0 \%$ & $-14.1 \%$ & $0.0 \%$ & $-4.4 \%$ \\
\hline Interest on canital & 60 & $\%$ & $8.0 \%$ & $0.0 \%$ & $7.7 \%$ & $0.0 \%$ & $2.4 \%$ \\
\hline interest on capital & 0.0 & $\%$ & $4.0 \%$ & $0.0 \%$ & $-7.0 \%$ & $0.0 \%$ & $-2.2 \%$ \\
\hline License cost & & & $+100 \%$ & $0.0 \%$ & $1.5 \%$ & $0.0 \%$ & $0.5 \%$ \\
\hline $\begin{array}{l}(0.5 \% \text { of total } \\
\text { sale/year })\end{array}$ & 0.16 & M€/year & $-100 \%$ & $0.0 \%$ & $-1.5 \%$ & $0.0 \%$ & $-0.5 \%$ \\
\hline Distribution system & parameters & & & & & & \\
\hline Distance to & 5 & & $+50 \%$ & $0.0 \%$ & $0.0 \%$ & $2.3 \%$ & $0.2 \%$ \\
\hline terminal & 5 & $\mathrm{Km}$ & $-50 \%$ & $0.0 \%$ & $0.0 \%$ & $-2.3 \%$ & $-0.2 \%$ \\
\hline Total road & $5+5$ & $\mathrm{~km}$ & $-100 \%$ & $0.0 \%$ & $0.0 \%$ & $-22.8 \%$ & $-2.2 \%$ \\
\hline
\end{tabular}


transport

Train distance

500

$\mathrm{km}$

$+50 \%$

$0.0 \% \quad 0.0 \%$

$18.1 \% \quad 1.7 \%$

$-50 \%$

$0.0 \% \quad 0.0 \% \quad-18.1 \% \quad-1.7 \%$ 
Table 6. Parameters in a "best-case" scenario

\begin{tabular}{|c|c|}
\hline Parameter & Justifications \\
\hline - Moisture content $=$ Base case & $\begin{array}{l}\text { - It is difficult to get drier wood residues directly from roadside } \\
\text { when all around year supply is performed. }\end{array}$ \\
\hline $\begin{array}{l}\text { - Amount of biomass }=+50 \% \text { and } \\
\text { biomass premium }=-25 \%\end{array}$ & $\begin{array}{l}\text { - There should be a possibility to find suitable places where there is } \\
\text { high yield and low competition of biomass, which renders a low } \\
\text { biomass premium. }\end{array}$ \\
\hline - Logistics equipment $=$ base case & - For cost reasons, shown in previous calculations. \\
\hline $\begin{array}{l}\text { - Winding factor, cost of } \\
\text { forwarding and cost of transport }= \\
\text { base case }\end{array}$ & $\begin{array}{l}\text { - An establishment at a new decentralised torrefaction plant at a } \\
\text { location with low competition probably does not have a highly } \\
\text { devolved road network and well developed logistic systems. }\end{array}$ \\
\hline - Plant availability $=98 \%$ & - Should be possible compared to other commercial pellet plants. \\
\hline - Drying technology = base case & $\begin{array}{l}\text { - As shown in previous calculation, this setup has best effects on } \\
\text { OPEX }\end{array}$ \\
\hline - Torrefaction mass yield $=87.2 \%$ & - This setup facilitates efficient flue gas condensation \\
\hline - Power generation $=$ base case & - For cost reasons, shown in previous calculations. \\
\hline - Flue gas condensation = yes & $\begin{array}{l}\text { - Due to OPEX optimisation together with mass yield and biomass } \\
\text { MC. }\end{array}$ \\
\hline $\begin{array}{l}\text { - Type of product storage }=\text { base } \\
\text { case }\end{array}$ & $\begin{array}{l}\text { - As shown in previous calculation, this setup has best effects on } \\
\text { OPEX }\end{array}$ \\
\hline - Scale factor $=$ base case & - Safe assumption, see previous discussion \\
\hline $\begin{array}{l}\text { - Cost of electricity, external } \\
\text { services and personnel = base case }\end{array}$ & - It's a safe assumption that these are most realistic. \\
\hline - CAPEX = -25\% & $\begin{array}{l}\text { - There are strong reasons to believe that due to technical } \\
\text { development and general progress towards the } \mathrm{n}^{\text {th }} \text { plant, } \\
\text { investments can be reduced by } 25 \% \text {. }\end{array}$ \\
\hline - Interest on capital = base case & - Safe assumption \\
\hline - License cost $=$ base case & - Due to realistic assumptions of future IPR \\
\hline $\begin{array}{l}\text { - Distance to terminal, total road } \\
\text { transport and train distance }=\text { base } \\
\text { case }\end{array}$ & $\begin{array}{l}\text { - Given that the plants are located in areas of low completion, it is } \\
\text { fair to assume that these are far from the customer and that } \\
\text { distances, hence, not will be lower. }\end{array}$ \\
\hline
\end{tabular}

